\title{
A produção científica sobre gênero: questões epistemológicas e curriculares
}

\section{Scientific production on gender: epistemological and curricular issues}

\section{La producción científica sobre género: cuestiones epistemológicas y curriculares}

José Licínio Backes ${ }^{1}$

DOI: http://dx.doi.org/10.20435/serie-estudos.v23i48.1129

\begin{abstract}
Resumo: O artigo tem como objetivo analisar a produção científica sobre gênero veiculada em periódicos classificados como A1 pela área de Educação da CAPES, no período 2010-2014. A análise centrou-se nas contribuições epistemológicas e curriculares desses estudos e mostrou que a produção de gênero tem colaborado para desconstruir a ideia de que existe uma epistemologia neutra e desinteressada, evidenciando que a ciência moderna é sexista, heterossexual e machista. Dessa forma, esta análise contribui para construir outras epistemologias, notadamente epistemologias que reconhecem o caráter político de toda e qualquer ciência. Em termos curriculares, os estudos de gênero auxiliam a mostrar que os currículos nas escolas continuam pautados na heteronormatividade, reproduzindo hierarquizações e violências de gênero. Contribuem, ainda, para demonstrar que a problematização das relações de gênero nos currículos é fundamental, pois o silenciamento e a não problematização têm sido estratégias eficientes de manutenção da heteronormatividade.
\end{abstract}

Palavras-chave: gênero; epistemologia; currículo.

Abstract: This paper aims to analyze the scientific production on gender in journals ranked as A1 by CAPES Education area in the 2010-2014 period. The analysis focused on the epistemological and curricular contributions from those studies and showed that the production on gender has contributed to deconstruct the idea that there is a neutral, disinterested epistemology by evidencing that modern science is sexist, heterosexual and male chauvinist. Hence, this analysis contributes to the construction of other epistemologies, particularly those that acknowledge the political character of every kind of science. In terms of curriculum, gender studies have shown that school curricula are still grounded on heteronormativity, thus reproducing gender hierarchization and violence. They have also evidenced that the problematization of gender relations in the curricula is fundamental, as silence and non-problematization have been effective strategies to maintain heteronormativity.

Keywords: gender; epistemology; curriculum.

\footnotetext{
${ }^{1}$ Universidade Católica Dom Bosco (UCDB), Campo Grande, Mato Grosso do Sul, Brasil.
} 
Resumen: El artículo tiene como objetivo analizar la producción científica sobre género difundida en periódicos clasificados como A1 por el área de educación de la CAPES, en el periodo 20102014. El análisis se centró en las contribuciones epistemológicas y curriculares de estos estudios, y mostró que la producción de género ha contribuido para acabar con la idea de que existe una epistemología neutra y desinteresada, evidenciando que la ciencia moderna es sexista, heterosexual y machista. De esta forma, este análisis contribuye para construir otras epistemologías, especialmente epistemologías que reconocen el carácter político de toda y cualquier ciencia. En términos curriculares, los estudios de género contribuyen para mostrar que los programas en las escuelas continúan pautados en la heteronormatividad, reproduciendo jerarquizaciones y violencia de género. Contribuyen para demostrar que la problematización de las relaciones de género en los programas de estudio es fundamental, ya que el silenciamiento y la no-problematización han sido estrategias eficientes de manutención de la heteronormatividad.

Palabras clave: género; epistemología; currículo.

\section{INTRODUÇÃO}

O artigo é resultado do projeto de pesquisa "Análise da produção científica de gênero, raça/etnia e currículo veiculada em periódicos de educação Qualis A1 (2010-2014) editados no Brasil: questões epistemológicas e curriculares", desenvolvido com o apoio do CNPq (Chamada Bolsa Produtividade Pq 2013). Tem como objetivo analisar questões epistemológicas e curriculares presentes em artigos que versam sobre gênero publicados no período 2010-14, em periódicos classificados como A1 pela área de Educação da CAPES, editados no Brasil.

Foram analisados os artigos de gênero dos seguintes periódicos: Revista Avaliação (UNISO), Cadernos de Pesquisa (Fundação Carlos Chagas), Educação em Revista (UFMG), Educação e Pesquisa (USP), Educação e Realidade (UFRGS), Educação \& Sociedade (UNICAMP), Educar em Revista (UFPR), Revista Ensaio (CESGRANRIO), ETD - Educação Temática Digital (UNICAMP), Pró-Posições (UNICAMP) e Revista Brasileira de Educação (ANPED). Não foram incluídos os artigos do periódicos A1 de outras áreas (História, Linguística, Literatura, Ciências Sociais, Antropologia, Ensino de Ciências, Psicologia), mesmo que avaliados como A1 também na área de Educação. Observa-se que o Qualis considerado foi o do triênio 2010-2012.

Ao todo, foram identificados 91 artigos sobre gênero no período analisado, representando 3,56\% de um total de 2.556 artigos. Esses artigos foram lidos na íntegra, tendo como foco identificar questões epistemológicas e curriculares, sobretudo, as contribuições que os estudos de gênero vêm dando ao campo epistemológico e curricular. 
No primeiro momento deste artigo, trazemos algumas questões epistemológicas, salientando como os estudos de gênero vêm contribuindo para desconstruir a concepção moderna de ciência em suas diferentes versões. Salientamos que as concepções modernas de ciência têm em comum a ideia de universalidade e objetividade (GALLO, 2006). Em um segundo momento, trazemos algumas questões curriculares, destacando como os estudos de gênero percebem o currículo e como contribuem para o seu processo de ressignificação, em um esforço epistêmico e político de construção de um currículo não pautado na lógica da heteronormatividade, mas em múltiplas lógicas. Por fim, fazemos algumas observações que mostram os caminhos percorridos, suas potencialidades e quais caminhos podem ser percorridos para potencializar outros currículos.

\section{ALGUMAS QUESTÕES EPISTEMOLÓGICAS}

Os estudos de gênero, nas últimas décadas, têm contribuído de forma significativa para mostrar a impossibilidade de uma epistemologia ser neutra e desinteressada. Mais do que isso, eles têm colaborado para mostrar o caráter sexista, machista e heterossexual da ciência moderna. Esta, apesar de sua apregoada imparcialidade, tem servido sistematicamente para fortalecer a dominação masculina, reforçando as hierarquias de gênero historicamente construídas: “[...] nenhuma pesquisa, ou melhor, nenhuma ciência é desinteressada ou neutra" (LOURO, 1997, p. 143). A pretensão da ciência moderna em falar em nome de todos não passa de uma quimera. No dizer de Louro (1997, p. 143),

Esta Ciência, escrita com maiúsculas, fala por todos, já que foi pensada, conduzida e instituída a partir dos interesses e das questões daqueles cujas vozes pretenderam (e pretendem) representar toda a humanidade. Mas essa Ciência também foi feita - é indispensável reconhecer isso - por um grupo ou uma parte da humanidade. Ela foi feita pelos homens - os homens brancos ocidentais da classe dominante - os quais, supostamente, fizeram as perguntas e deram as respostas que interessavam a todas as pessoas.

Apesar de a crítica de Louro (1997) ter sido feita há duas décadas, a desconstrução da ciência moderna continua sendo um desafio dos mais complexos e difíceis, sobretudo no contexto brasileiro, no qual, desde o golpe midiático/ jurídico parlamentar de 2016, que depôs a Presidente da República legitimamente eleita, se observa a intensificação de uma onda conservadora. O "Golpe de Estado consumado em 31 de agosto de 2016, [...] aprofunda o projeto de capitalismo 
dependente e [...] fecha novamente um circuito de nossa história com as marcas da dominação autoritária e consequente ruptura do Estado de Direito" (RAMOS; FRIGOTTO, 2016, p. 45). Embora, para os autores, os interesses econômicos sejam os que mais contribuíram para o golpe de 2016, não se pode deixar de reconhecer que a aliança conservadora também tem atingido, de modo aterrador, as discussões de gênero no campo do currículo, boicotando a inclusão de políticas educativas nas escolas, o que poderia colaborar para a desconstrução do sexismo, da homofobia e do machismo.

Apesar desse movimento conservador, a luta dos movimentos de gênero continua, bem como a produção científica, ainda que em um contexto de escassez de recursos financeiros. A onda conservadora, de forma explícita ou não, está baseada nos pressupostos da ciência moderna, que, como os próprios estudos de gênero vêm denunciando, se fundamenta na ideia de um sujeito universal, que a rigor é um sujeito particular (homem, masculino, branco, classe dominante) imposto como universal, recorrendo sistematicamente ao uso da violência física e simbólica. Conforme os estudos de gênero mostram, assim como as violências cotidianas de gênero, seja contra as mulheres, seja contra os sujeitos não heterossexuais, essa violência continua marcando as relações de gênero no Brasil.

Nessa crítica à ciência moderna, que se pretende universal e imparcial, tanto os estudos críticos quanto os pós-críticos têm sido fundamentais. No campo dos estudos de gênero, esses dois campos também têm sido muito vigorosos. Nesse sentido, em relação às questões epistemológicas presentes nos artigos de gênero, pode-se afirmar que se situam no campo crítico e pós-crítico da educação. A articulação desses campos produz epistemologias híbridas, estabelecendo articulações produtivas com os estudos de gênero.

Salientamos que por campo pós-crítico entendemos, com Paraíso (2004, p. 284), que se trata de um campo múltiplo que "[...] recebe influências da chamada 'filosofia da diferença', do pós-estruturalismo, do pós-modernismo, da teoria quer, dos estudos feministas e de gênero, dos estudos multiculturalistas, pós-colonialistas, étnicos, ecológicos, etc." (PARAísO, 2004, p. 284). Esses estudos apontam "[...] para a abertura, a transgressão, a subversão, a multiplicação de sentidos e para a diferença" (PARAÍSO, 2004, p. 285), transformando os currículos e as epistemologias. Já o campo crítico, entendemos que está centrado "[...] na análise dos mecanismos pelos quais a sociedade capitalista contemporânea tende a ampliar 
suas formas de dominação cultural e ideológica" (SILVA, 2000, p. 105), o que, no campo da Educação, significa privilegiar o "[...] questionamento do papel que a escola, o currículo e a pedagogia exercem na produção e reprodução de formas de dominação de classe" (SILVA, 2000, p. 106). Nos artigos de gênero analisados, há o reconhecimento de que não existe neutralidade epistemológica. Essa não neutralidade é sustentada com argumentos dos autores, conforme a temática investigada. Os estudos de gênero criticam a epistemologia ocidental por ela ser sexista, machista e heterossexual.

Nos estudos de gênero analisados, as epistemologias têm uma influência maior dos estudos considerados pós, com destaque para os estudos feministas. Esses estudos têm se ocupado com diferentes questões, mas sobressaem-se os que mostram a pluralidade de formas de viver as identidades de gênero, apesar de o currículo e a sociedade procurarem impor a heterossexualidade como padrão único, por meio de uma epistemologia construída na modernidade também com pretensões de ser a única válida. Santos $(2007 ; 2008)$ a denomina de fascismo epistemológico: "o fascismo epistemológico existe sob a forma de epistemicídio, cuja versão mais violenta foi a conversão forçada e a supressão dos conhecimentos não ocidentais levadas a cabo pelo colonialismo europeu e que continuam hoje sob formas nem sempre subtis" (SANTOS, 2008, p. 28). Os estudos de gênero analisados demonstram que esse fascismo epistemológico esteve e continua presente em relação às identidades de gênero, instituindo-as fora da lógica da heterossexualidade como desviantes e anormais. Porém, apesar desse fascismo, as identidades de gênero continuam plurais, e o campo dos estudos de gênero tem tido um papel relevante para desconstruir o fascismo, recorrendo a diferentes epistemologias que não têm a pretensão de tornarem-se únicas e universais.

Articulados com as epistemologias identificadas, estão os procedimentos metodológicos. Nesse sentido, observa-se que os artigos se inserem no rol das pesquisas qualitativas em Educação quando lidam com pesquisa de campo, geralmente tratando de realidades específicas e poucos sujeitos. Na maioria dos artigos, não há preocupação em justificar o uso de um determinado procedimento metodológico, que em geral é anunciado suscintamente. A recorrência das pesquisas qualitativas não significa que dados quantitativos não sejam utilizados nos artigos, mas eles são citados a partir dos bancos de dados produzidos por outros, com destaque para os dados do Instituto Nacional de Estudos e Pesquisas Anísio 
Teixeira (INEP) e do Instituto Brasileiro de Geografia e Estatística (IBGE). Cabe destacar também que as pesquisas buscam analisar e compreender como se dão as relações de gênero, notando-se pouca presença das modalidades de pesquisa-ação, pesquisa-intervenção, pesquisa participante ou, ainda, etnopesquisa-ação e etnopesquisa-formação (MACEDO, 2006).

Com as epistemologias e procedimentos metodológicos presentes nos artigos de gênero, os estudos analisados mostram que:

a) As escolas tendem a ser espaços de reprodução e reforço da visão hegemônica que controla as sexualidades e privilegia a heterossexualidade: os artigos apontam que persistem as dificuldades em discutir as políticas públicas relacionadas com igualdade de gênero, redução da homofobia, prevenção de doenças, direitos humanos e outras. A homofobia ainda é praticada contra as pessoas que não vivem no modelo heteronormativo. Essas pessoas são excluídas, estigmatizadas e, por vezes, assassinadas física ou psicologicamente. Há, ainda, um silenciamento docente nas práticas curriculares porque os professores e as professoras não sabem como atuar. Os professores costumam ver o constrangimento e a aflição provocados em função das relações de gênero como brincadeiras típicas de crianças, adolescentes ou jovens. (TEIXEIRA FILHO; RONDINI; BESSA, 2011).

b) As relações de gênero baseadas na heteronormatividade produzem violência nas escolas e na sociedade: os professores têm dificuldade de perceber as formas de violência vinculadas a questões de gênero nas escolas, tendendo a vê-las como violência sem relação com gênero. Crianças e jovens que subvertem a ordem, a norma e o gênero podem despertar ódio: "[...] o desejo de matar alguém que transgrida a norma do gênero é gerado a partir de um ódio à transgressão da norma do gênero (masculino ou feminino): viver significa estar dentro desta norma e aqueles/as que não estão não merecem viver" (CESAR, 2012, p. 357). É preciso criticar as visões que tratam a subalternização, inferiorização, invisibilização e outros preconceitos e discriminações como um simples bullying, pois: "a retórica do bullying faz as manifestações homofóbicas e sexistas serem tratadas como uma violência de indivíduos, apolítica, desligada das normas sociais que estabelecem quais vidas são verdadeiramente dignas de respeito e de existência pública" (OLIVEIRA; DINIZ, 2014, p. 249).

c) A reprodução da heteronormatividade ocorre não necessariamente de forma intencional e planejada: a reprodução ocorre, sobretudo, nas relações 
cotidianas da sala de aula e de outros espaços de maneira informal, por exemplo, pela "[...] tecnologia da zoação, a qual é composta por várias técnicas, como o sarcasmo, a ironia, o deboche, o repúdio, o banimento" (SALES; PARAísO, 2013, p. 605). Os meninos são sistematicamente cobrados a manterem a heterossexualidade viçosa, afastando qualquer vestígio de homossexualidade.

d) Ainda há carência de materiais didáticos para discutir as relações de gênero: os livros e materiais didáticos distribuídos e os conteúdos são antagônicos em relação às questões de gênero e sexualidade. "Políticas anti-homofóbicas e antissexistas estão na pauta das agendas pedagógicas do Ministério da Educação. Entretanto a heteronormatividade constitui o marco epistêmico da retórica pedagógica oficial dos livros didáticos aprovados e distribuídos pelo MEC" (OLIVEIRA; DINIZ, 2014, p. 242). As concepções de gênero aparecem naturalizadas e como universais, sendo que a sexualidade, quando discutida, é em termos biológicos ou psicológicos. Assim, "as figurações da sexualidade e do gênero desses materiais performam um mundo em que diferenças e subalternidades são lidas como parte da vida psicológica" (OLIVEIRA; DINIZ, 2014, p. 248).

e) Para mudar as relações de gênero, é preciso colocar em xeque a heteronormatividade: nas escolas e na sociedade, ainda predomina a heteronormatividade, procurando-se impor uma forma única de viver a sexualidade e a identidade de gênero, seja por meio dos silenciamentos, das crenças cristalizadas, do despreparo dos docentes, da cultura machista, heterossexual e cristã, ou ainda, pela redução da violência de gênero aos casos de bullying, como se fosse uma questão de aceitação ou apenas de cunho psicológico, e não uma produção histórica e social, como apontam os autores estudados. Nesse sentido, a heteronormatividade precisa ser colocada em xeque, viabilizando a existência de todas as formas de sexualidade e identidades de gênero. Urge "[...] aprender a viver em um mundo mais aberto, o que implica uma rearticulação do humano, isto é, a destruição das evidências e das certezas ou aprender a lidar com o desconhecido" (CÉSAR, 2012, p. 360).

f) As relações de gênero presentes nos currículo estão marcadas pela heteronormatividade, sexismo e homofobia: recorrentemente nos currículos, a heteronormatividade é reforçada, dificultando a transformação das relações de gênero: "a norma que orienta os modos de ver e compreender os corpos e a vida reitera um sistema de injustiças, de diferenças subalternizantes, sob o disfarce da universalidade e/ou da natureza" (OLIVEIRA; DINIZ, 2014, p. 251). 
g) Os conceitos de identidade, diferença, gênero e heteronormatividade são centrais nas discussões das relações de gênero nos artigos analisados: as ênfases biológicas e essencialistas que ainda marcam esses conceitos, dificultando a superação do sexismo, da homofobia e da violência, são sistematicamente criticadas nos artigos analisados. Ao mesmo tempo que criticam essas ênfases, os artigos apoiam-se na concepção de identidades e diferenças como sendo construções históricas e culturais, que foram inventadas e não são naturais. No campo da Educação, importa mostrar "[...] que sexo, gênero e corpo são invenções culturais, linguísticas e institucionais, geradas no interior das relações de saber-poder-prazer; e, sobretudo, determinadas nos limites do pensamento ocidental moderno" (CÉSAR, 2012, p. 360). A educação, em seus diferentes níveis e modalidades, pode tanto servir para reproduzir as relações hegemônicas, quanto para questioná-las ou subvertê-las. Os artigos mostram que ainda persiste, nos diferentes espaços educativos, a tendência de reproduzir relações sexistas, machistas e discriminatórias. Especificamente no campo de gênero, um conceito que também é recorrente é o de heteronormatividade. Ele impõe como normal a lógica heterossexual, desqualificando todas as demais identidades de gênero, que tendem a ser vistas como patológicas e anormais.

[...] heteronormatividade é um dispositivo hierarquizante cujas regras naturalizantes (tidas como autoevidentes) tornam o que a elas escapa um erro, uma exceção, uma abjeção. Esse sistema de inteligibilidade é o horizonte sobre o qual emergimos como sujeitos, e em que aprendemos a sentir, pensar, falar, existir. Esse marco rege a inteligibilidade dos corpos, estabelece o que é cognoscível, condiciona as formas de reconhecimento dos corpos por meio de características que serão consideradas óbvias, visíveis e, até mesmo, presumíveis. (OLIVEIR; DINIZ, 2014, p. 250).

Como já destacado, há um permanente questionamento dessa lógica nos artigos analisados, salientando-se a necessidade de desconstruí-la para que outras relações de gênero possam ser construídas. Mesmo que possa parecer óbvio, deve-se salientar que o conceito de gênero é recorrentemente mencionado nos artigos. Com ele, colocam-se em xeque concepções naturais e essencializadas de identidades, mostrando seu caráter construído. 


\section{ESTUDOS DE GÊNERO E QUESTÕES CURRICULARES}

Em relação à concepção de currículo que permeia os estudos de gênero, pode-se afirmar que, em nenhum deles, o currículo é visto como um documento que apenas é aplicado em sala de aula, tampouco é visto como um conjunto de conhecimentos neutros e desinteressados. Ele é considerado como fruto de uma seleção: "o currículo escolar, portanto, é central na construção de diferenças e das identidades, e não um dispositivo neutro com eixo apenas na transmissão de conhecimentos (concebidos como fatos, como informação)" (SILVA; SIQUEIRA; LACERDA, 2010, p. 238).

Nesse sentido, os estudos de gênero denunciam que há um reforço sistemático da heteronormatividade no campo do currículo: "pessoas que se distanciam da normatização heterossexista e da visão essencialista, que associa gênero a identidade social e a identidade sexual, são estigmatizadas e perseguidas de diferentes formas em instituições escolares" (DINIS; PAMPLONA, 2014, p. 228). Esse reforço sistemático da heteronormatividade contribui para a reprodução da violência de gênero: "heteronormatividade e violência sexista e homofóbica são polos de um mesmo campo de inteligibilidade dos corpos. Há uma injustiça intolerável: as normas excludentes e hierarquizantes do sistema de gênero" (OLIVEIRA; DINIZ, 2014, p. 252).

Entretanto, apesar das várias formas de controle, fiscalização e tentativas de fixação do currículo, ele sempre acaba sendo mais do que o currículo proposto pelos órgãos oficiais. Apesar da hegemonia da lógica heterossexual no currículo e suas inúmeras formas de avaliação, que geram um reducionismo curricular e uma responsabilização de docentes e discentes, outros currículos continuam sendo praticados. O currículo é visto como um campo de forças em que diferentes agentes disputam espaço para impor suas demandas. Ele nunca está dado, sendo permanentemente reconfigurado pelas lutas/tensões sociais, tanto do campo conservador (mercado/fundamentalismo religioso) quanto do campo crítico e pós-crítico, com destaque para os movimentos sociais de gênero, raça/etnia e do campo popular. A análise "[...] aponta que a produção da heterossexualidade não se dá de forma harmônica e/ou sem disputas bem como sinaliza que a heteronormatividade investe na normalização do seu modelo identificatório legitimado -a heterossexualidade" (DORNELLES; POCAHY, 2014, p. 119). 
Portanto pode-se afirmar que os artigos de gênero têm sido impactantes no campo do currículo, sobretudo em duas dimensões: a) para denunciar o caráter sexista e heteronormativo do currículos escolares por meio de seu documentos, artefatos culturais, materiais didáticos, posturas docentes e relações pedagógicas, que reforçam a ideia de que existe uma identidade de gênero padrão e universal à qual todos invariavelmente devem aderir, sob pena de serem vistos como doentes, desviantes, anormais; b) para contribuir na construção de currículos plurais em que a diferença seja vista não como desviante ou patológica, mas como característica constitutiva dos grupos e sujeitos humanos. Apesar do momento conservador do Brasil, há um conjunto de transformações que, junto com os estudos de gênero, "[...] têm desestabilizado as identidades vistas como fixas e imutáveis. No lugar disso, a fragmentação e a contingência das identidades têm abalado certezas de um sujeito único e essencial e seus quadros de referência" (SILVA; SOARES, 2014, p. 138).

\section{ALGUMAS OBSERVAÇÕES FINAIS}

A pesquisa evidenciou que, nos estudos de gênero, a ênfase está em mostrar como a temática das relações de gênero está pouco presente ou ausente nos currículos e que há pouco ou nenhum questionamento da heteronormatividade. Talvez o próximo passo a ser dado seja apostar em outras formas de pesquisa, mais precisamente em pesquisa-ação, pesquisa-intervenção, pesquisa participante ou, ainda, etnopesquisa-ação e etnopesquisa-formação (MACEDO, 2006), posto que essas modalidades de pesquisa estão quase ausentes nos artigos analisados. O aumento dessas modalidades de pesquisa poderá contribuir para diminuir o abismo existente entre o que os pesquisadores do campo das relações de gênero apontam sobre a forma como essas questões devem ser trabalhadas e como efetivamente são trabalhadas no currículo. Além de saber da existência e da permanência da heteronormatividade, do sexismo e da violência de gênero, urge saber como efetivamente eles podem ser desconstruídos nas escolas. Mais pesquisas que proponham intervenções podem ser um caminho promissor para encontrar pistas.

Observou-se também que a maior parte das pesquisas se refere à educação básica. Embora reconheça-se a importância de pesquisar a educação básica, não se pode deixar de apontar que há uma lacuna na pesquisa sobre a articulação 
entre educação superior e relações de gênero, sobretudo em tempos em que a presença de outros sujeitos nas universidades tem se ampliado via políticas de ação afirmativa.

Uma questão que é recorrente nas pesquisas feitas na educação básica é a falta de uma formação adequada, apontada tanto pelos pesquisadores quanto por professores da educação básica na condição de sujeitos da pesquisa: "entre os professores que indicaram não se sentirem preparados para o trabalho com a diversidade, relacionaram essa dificuldade à formação, ao tipo de traços da diversidade, aos posicionamentos e valores e às características do contexto atual" (EYNG et al., 2013, p. 785). Nesse sentido, seria importante que houvesse uma preocupação maior em pesquisar a educação superior, sobretudo as licenciaturas, a fim de compreender como a formação inicial está incorporando ou não a discussão sobre as relações de gênero no currículo, bem como se está formando (ou não) para o questionamento da heteronormatividade.

Outra observação a ser feita é que, nos estudos de gênero, são mais privilegiadas as identidades que não seguem a heteronormatividade. Os estudos que problematizam a identidade masculina heterossexual branca não são tão recorrentes, o que pode contribuir, ainda que não seja essa a intenção, para levar ao entendimento de que há identidades em crise e problemáticas (identidades não heterossexuais), enquanto há uma identidade normal, intocável, natural (a heterossexual).

A invisibilidade da norma é condição importante para a sua eficácia, silenciando sobre os mecanismos que nos fazem tomar algumas identidades (a identidade de gênero heterossexual, por exemplo) como comportamentos que não precisam dizer de si, não precisam ser problematizados. (SEFFNER, 2013, p.157).

A pouca presença de estudos sobre sujeitos heterossexuais/masculinos/ brancos é uma lacuna que precisa, segundo nossa análise, ser resolvida urgentemente, sob pena de, ao invés de construirmos um currículo mais plural, mantermos as relações de gênero hierarquicamente construídas e sustentadas pela heteronormatividade. Talvez uma forma de potencializar a desconstrução da heteronormatividade, sem abrir mão de pesquisar a educação básica, seja pesquisar o stricto sensu para percebermos o quanto a heteronormatividade está presente em nosso modo de educar e pesquisar, o quanto estamos imersos na heteronormatividade 
do poder, do ser e do viver. Dizemos uma forma de potencializar porque, segundo nossa análise, os estudos na educação superior relacionados às questões de gênero não têm sido recorrentes, muito menos os que envolvem os pesquisadores e formadores de pesquisadores que atuam no stricto sensu. Talvez esse seja mais um caminho promissor para ajudar a transformar os currículos.

\section{REFERÊNCIAS}

CÉSAR, Maria Rita de Assis. A diferença no currículo ou intervenções para uma pedagogia. ETD - Educação Temática Digital, v. 14, n. 1, p. 351-62, jan./jun. 2012.

DINIS, Nilson Fernandes; PAMPLONA, Renata Silva. Encontrando Bianca: discursos sobre corpo-travesti. Pró-Posições, Campinas, SP, v. 25, n. 2, p.217-36, maio/ago. 2014.

DORNELLES, Priscila G.; POCAHY, Fernando A. Prendam suas bezerras que o meu garrote está solto. Educar em Revista, Curitiba, edição especial, n. 1, p. 117-33, 2014.

EYNG, Ana Maria et al. Diversidade e padronização nas políticas educacionais; configurações da convivência escolar. Revista Ensaio, Rio de Janeiro, v. 21, n. 81, p. 773-800, 2013.

GALLO, Sílvio. Modernidade/pós-modernidade: tensões e repercussões na produção de conhecimento em educação. Educação e Pesquisa, São Paulo, v. 32, n. 3, p. 551-65, set./ dez. 2006.

LOURO, Guacira Lopes. Gênero, sexualidade e educação: uma perspectiva pós-estruturalista. Petrópolis, RJ: Vozes, 1997.

MACEDO, Roberto Sidnei. Etnopesquisa crítica e etnopesquisa-formação. Brasília: Líber, 2006.

OLIVEIRA, Rosana Medeiros de; DINIZ, Débora. Materiais didáticos escolares e injustiça epistêmica: sobre o marco heteronormativo. Educação \& Realidade, Porto Alegre, RS, v. 39, n. 1, p. 241-56, jan./mar. 2014.

PARAíso, Marlucy Alves. Pesquisas pós-críticas em educação no Brasil: esboço de um mapa. Cadernos de. Pesquisa, São Paulo, v.34, n.122, p. 283-303, 2004.

RAMOS, Marise Nogueira; FRIGOTTO, Gaudêncio. Medida Provisória 746/2016: a contra-reforma do ensino médio do golpe de estado de 31 de agosto de 2016. Revista HISTEDBR, Campinas, SP, n. 70, p. 30-48, dez. 2016.

SALES, Shirlei Rezende; PARAÍSO, Marlucy Alves. O jovem macho e a jovem difícil: governo da sexualidade no currículo. Educação \& Realidade, Porto Alegre, RS, v. 38, n. 2, p. 603-25, abr./jun. 2013.

SANTOS, Boaventura de Sousa. A filosofia à venda, a douta ignorância e a aposta de Pascal. Revista de Ciências Sociais, Coimbra, Portugal, n. 80, p. 11-43, mar. 2008. 
. Para além do pensamento abissal: das linhas globais a uma ecologia de saberes. Novos Estudos CEBRAP, São Paulo, n. 79, p. 71-94, nov. 2007.

SEFFNER, Fernando. Sigam-me os bons: apuros e aflições nos enfrentamentos ao regime da heteronormatividade no espaço escolar. Educação e Pesquisa, São Paulo, v. 39, n. 1, p. 145-59, 2013.

SILVA, Andrea da Costa; SIQUEIRA, Vera Helena FERRAZ de; LACERDA, Nilma. Gonçalves. Literatura e sexualidade: visibilidades e silenciamentos nas apropriações docentes. Educação \& Realidade, Porto Alegre, RS, v. 35, n. 1, p. 233-51, 2010.

SILVA, Tomaz Tadeu. Teoria cultural e educação: um vocabulário crítico. Belo Horizonte: Autêntica, 2000.

SILVA, Rosimeri Aquino da; SOARES, Rosângela. Sexualidade e identidade no espaço escolar: notas de uma atividade em um curso de educação à distância. Educar em Revista, Curitiba, edição especial, n. 1 m p. 135-51, 2014 .

TEIXEIRA-FILHO, Fernando Silva; RONDINI, Carina Alexandra; BESSA, Juliana Cristina. Reflexões sobre homofobia e educação em escolas do interior paulista. Educação e Pesquisa, São Paulo, v. 37, n. 4, p. 725-41, dez. 2011.

\section{Sobre o autor}

José Licínio Backes: Doutorado em Educação pela UNISINOS. Pós-doutorado em Educação pela UMINHO. Professor do Programa de Pós-graduação em Educação - Mestrado e Doutorado, da Universidade Católica Dom Bosco (UCDB). E-mail: backes@ucdb.br

\section{Recebido em fevereiro de 2017 \\ Aprovado em março de 2018}


